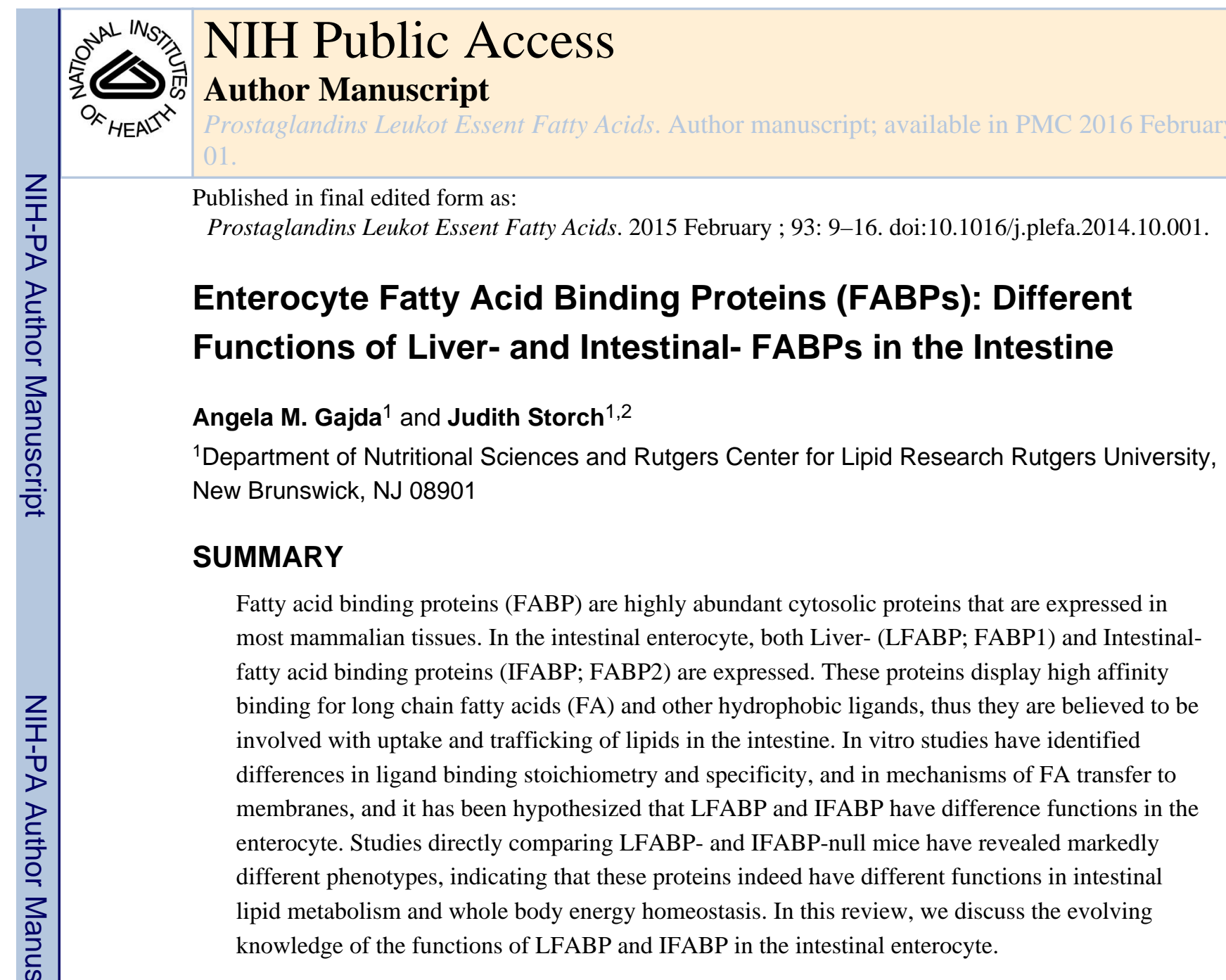

\title{
Keywords
}

fatty acid binding protein; fatty acid; intestine; lipid; LFABP; IFABP

\section{FATTY ACID BINDING PROTEINS}

The fatty acid binding protein (FABP) family is comprised of $14-15 \mathrm{kD}$ size intracellular proteins which were discovered beginning in the 1970s [1,2]. Presently, there are 9 known FABPs that are present in high abundance (1-5\%) in the cytosol of most tissues, plus the related cellular retinoid binding proteins [3,4]. The names for the proteins came from the tissue in which they were initially identified, but since some FABPs are expressed in multiple tissues, a numeric nomenclature is in use as well [5]. The FABPs display high affinity for binding to long chain (>14 C) fatty acids (FA). While these proteins have been

\footnotetext{
(C) 2014 Elsevier Ltd. All rights reserved.

${ }^{2}$ To whom correspondence may be addressed: Judith Storch, Department of Nutritional Sciences, Rutgers University, 65 Dudley Road, New Brunswick, NJ 08901, Storch@ aesop.rutgers.edu, Tel: (848) 932-1689, Fax: (732) 932-6837.

Publisher's Disclaimer: This is a PDF file of an unedited manuscript that has been accepted for publication. As a service to our customers we are providing this early version of the manuscript. The manuscript will undergo copyediting, typesetting, and review of the resulting proof before it is published in its final citable form. Please note that during the production process errors may be discovered which could affect the content, and all legal disclaimers that apply to the journal pertain.
} 
studied for over 40 years, it remains uncertain why they are so highly expressed, and why there are so many different FABPs; their specific functions are still being elucidated [3].

The FABPs have a highly conserved tertiary structure, consisting of 2 antiparallel $\beta$-sheets with 5 strands each, forming a "clam shell" or $\beta$-barrel in which the ligands are bound. In the barrel interior, positively charged amino acids interact with the carboxylate anion of the FA [6]. A short helix-turn-helix motif connects $\beta$-strands A and B and has been shown to be important for the mechanism of ligand transfer $[10,11]$. Despite the tertiary structural similarities between these proteins, they have only about $20-70 \%$ amino acid homology $[9,10]$, suggesting the possibility of functional specificities.

Recently, several FABPs were identified as carriers of anandamide (arachidinoylethanolamide or AEA) [11]. AEA is an N-acylethanolamine (NAE), a group of lipids that are formed by the hydrolysis of n-acylphosphatidylethanolamines (NAPEs) by Nacylphosphatidylethanolamine-phophospholipase $\mathrm{D}$, and have been shown to regulate food intake [12]. AEA was the first endocannabinoid identified in the NAE family of lipid signaling molecules. It was initially discovered in pig brain and found to have properties similar to $\Delta^{9}$-tetrahydrocannabinol, the active ingredient in cannabis, hence "ananda", bliss in Sanskrit, was used for the name of this lipid [13]. AEA regulates food intake by acting as an agonist of cannabinoid receptors 1 and $2\left(\mathrm{CB}_{1}\right.$ and $\left.\mathrm{CB}_{2}\right)$ on the plasma membrane. Similarly to $\Delta^{9}$-tetrahydrocannabinol, increased concentrations of AEA result in an acute increase in food consumption [11]. Additionally, 2-arachidonoylglycerol (2-AG), a monoacylglycerol (MG), has been identified as an endocannabinoid, with increased brain levels associated with greater food intake levels [14,15]. Moreover, Liver FABP has been recently identified as a carrier of MGs [16]. Hence, it has been hypothesized that the FABPs are involved with transport of NAEs and 2-AG, perhaps to the ER where they are hydrolyzed by fatty acid amide hydrolase (FAAH) or monoacylglycerol lipase (MGL), respectively, a critical step in the regulation of these lipids. Since the NAEs and 2-AG are known to play important roles in ingestive behavior, these observations raise the possibility that the FABPs may play important roles in the regulation of food intake.

\section{FABPS IN THE INTESTINAL ENTEROCYTE}

The intestinal enterocytes are responsible for processing the hydrolysis products of dietary lipids. Intestinal absorption of lipids is highly efficient, with greater than $95 \%$ of dietary lipid taken up [17]. It is generally thought that the presence of lipid binding proteins is critical for this capacity, particularly because levels of FABPs are very high in cytosol [3]. In the intestinal enterocyte, two FABPs are present, largely in the absorptive intestinal villus cells, but not in crypt cells [18]. Liver-type FABP (LFABP; FABP1) was the first protein identified in the FABP family. As the name suggests, it was initially discovered in the liver, but was later found in the intestine and also to a lesser extent in the kidney [3]. Intestinal FABP (IFABP; FABP2) is also present in the enterocyte and is solely expressed in this tissue [3]. Although these proteins share only about $29 \%$ amino acid sequence homology, their tertiary structures are quite similar. Humans express more LFABP than IFABP in the intestine [19,20], however mice have similar levels of both [19-21]. Expression of both proteins in the mouse occurs as early as 13 weeks of gestation [19]. 
In addition to LFABP and IFABP, the Ileal lipid or Bile acid binding protein (ILBP or BABP; FABP6) is present in the distal region of the small intestine and has a high affinity for binding bile acids. ILBP can bind FA, but with lower affinity than for bile acids [22]. ILBP has $\mathrm{K}_{\mathrm{d}}$ values for FA in the micromolar range, which stands in contrast to LFABP and IFABP which have $K_{d}$ values in the nanomolar range [23,24]. Expression of ILBP is increased in response to the presence of bile acids [25-27]. The gene for ILBP has a Farnesoid X receptor response element for binding to the Farnesoid $\mathrm{x}$ receptor (FXR) transcription factor, of which bile acids serve as ligand activators. Mice null for ILBP have increased fecal excretion of bile acids and did not have any changes in protein expression of LFABP in the intestine [28], suggesting an absence of functional overlap; IFABP levels were not reported

\section{LFABP}

LFABP is a highly abundant intracellular protein in the intestinal enterocyte. It is present throughout the intestine, but it is most highly expressed in the duodenum and jejunum [29]. In vitro studies have shown that LFABP binds FA with high affinity, with $\mathrm{K}_{\mathrm{d}}$ values in the nanomolar range [30,31]. LFABP is also unique among the FABPs in that it has two FA binding sites, and thus has a higher binding capacity than other FABPs. It has also been shown to bind to other lipid species including lysophospholipids, monoacylglycerols (MG), fatty acyl CoAs, and prostaglandins [3]. LFABP is also unusual in that, unlike most proteins in the FABP family, it transfers FA to membranes via a diffusional mechanism rather than by a direct 'collisional' interaction with membranes $[32,33]$. The subcellular distribution of LFABP in the enterocyte seems to be dependent on the feeding status, as LFABP is found throughout the cytosol of the enterocyte during times of FA availability, but the fasted state results in a more apical localization of this protein [34]. LFABP is also proposed to play an important role in the budding of prechylomicron transport vesicles (PCTVs) from the endoplasmic reticulum [35]. These PCTVs are further processed in the Golgi to mature chylomicrons that leave the enterocyte and enter the lymph and subsequently the general circulation, for delivery of dietary lipid to other tissues.

The promoter region of the LFABP gene has a peroxisome proliferator receptor element (PPRE) and thus, its expression is regulated by peroxisome proliferator activated receptor transcription factors (PPARs) [36]. In particular, PPARa is present in the liver and intestine and when bound to ligands such as LCFA and fibrates, will increase transcription of genes involved with oxidation of lipids [37]. Indeed, administration of PPARa agonists such as bezafibrate and clofibrate results in increased transcription of LFABP mRNA in mouse intestine and liver [21,38]. Interestingly, several studies have investigated a role for LFABP in the regulation of genes involved with lipid metabolism, including fatty acid oxidation, via delivery of FA to transcription factors. LFABP has been demonstrated to interact with PPARa, whose target genes include those encoding fatty acid oxidation enzymes, and more recently to interact with $\mathrm{HNF} 4 \mathrm{a}$, a steroid hormone receptor known to promote transcription of genes involved with inflammation in the liver and intestine [39-42]. This putative role of LFABP in the regulation of gene expression is further supported by evidence that oxidation of FA is reduced in the absence of LFABP in the liver [40,43] and in the intestine [44,45]. LFABP expression is also regulated by increased dietary intake of lipids, as high-fat feeding 
provides increased levels of fatty acids to the intestine and liver while also increasing expression of LFABP in these tissues [1,38,46-49]. Female rats express higher levels of LFABP in hepatocytes than males, indicating that gender also influences expression of the protein $[21,50]$.

\subsection{POLYMORPHISM OF LFABP}

There have been no reported cases of deletion of the LFABP gene in humans, however a human polymorphism has been described in several recent reports [51,52]. A substitution of alanine for threonine at position 94 (T94A) of LFABP has been identified as a polymorphism that is associated with increased plasma TG and FFA levels [52,53]. Chang liver cells transfected with this variant form of LFABP have reduced uptake of FA, but additional accumulation of cholesterol relative to cells transfected with the wild-type protein [54]. Interestingly, human subjects who carry the A94 allele of LFABP had a blunted response in plasma TG levels relative to carriers of the T94 allele when they were treated with fenofibrate, an activator of PPARa, therefore it is hypothesized that the variant form of LFABP may be insufficient for delivery of fibrates to PPARa [52]. Indeed, human hepatocytes that express the A94 form of LFABP show reduced expression of PPARa regulated genes in response to fenofibrate than those expressing the WT T94 form [55], providing further evidence that LFABP is involved with PPARa-mediated lipid metabolic pathways.

\section{IFABP}

Unlike LFABP, IFABP is solely expressed in intestinal enterocytes of mammals. While IFABP is present throughout the small intestine; its highest expression is in the jejunum [56]. Like LFABP, IFABP is found widely distributed throughout the cytosol of the enterocyte during the fed state, but is localized towards the apical side of the cell in the fasted state [34]. IFABP has not been found to be involved with chylomicron formation [35,57], hence IFABP has been proposed to be involved with uptake of FA from the lumen of the intestine, and with trafficking within the intestinal enterocyte to organelles [34]. It is also thought that both FABPs may serve as a cytosolic reservoir for FA required for various cellular functions, while also preventing accumulation of unesterified FA, which are known to modify membrane properties [4].

IFABP is typical among the members of the FABP family in that it has a single site where its FA ligand is bound. It has high affinity for binding saturated and unsaturated FA, but seems to have a somewhat lower affinity for binding unsaturated FA compared to LFABP $[30,31,58]$. Thus far, binding of ligands other than FA has not been reported for IFABP. Unlike LFABP, IFABP is similar to other proteins in the FABP family in that it transfers FA to membranes via a collisional mechanism [33]. The helix-turn-helix region of IFABP contains several positively charged residues that interact with negatively charged phospholipid head groups on membranes [59]. Fluorescence resonance energy transfer assays using a variant of IFABP, an engineered protein in which the alpha helices of IFABP are replaced with those of LFABP, have shown reduced transfer rates and a diffusional mechanism of FA transfer [59]. In contrast, when the alpha helices of IFABP replaced those of the native LFABP protein, a collisional mechanism was evident $[7,59]$. Hence, the alpha- 
helices of IFABP are required for direct interaction with membranes and for transfer of the ligands via protein-membrane collisional interaction [7,33].

Expression of IFABP in the intestine is influenced by PYY (peptide tyrosine tyrosine), a hormone which is released by intestinal cells in response to lipids in the gut [60]. In mice, expression of IFABP in the intestine does not increase in response to ablation of LFABP and vice-versa $[44,61,62]$. Unlike LFABP, expression of IFABP does not seem to be regulated by PPARs [63], These differences in regulation, and the lack of compensaory upregulation in the gene knockout mice, provide further evidence that these proteins may have different functions.

\subsection{POLYMORPHISM OF IFABP}

Deletion of the IFABP gene has not been reported in humans, however a polymorphism has been identified in which threonine is substituted for alanine at amino acid 54 (A54T) [64]. This amino acid substitution (frequency in the population of $\sim 0.29$ ) results in an increase in affinity for FA relative to the alanine-containing protein $[32,64]$. Individuals with the threonine-containing variant were found to have higher rates of insulin resistance and plasma triglycerides in several populations, including Pima Indians, a population with a very high prevalence of diabetes [64-68]. Additionally, diabetic subjects with the threonine allele have increased plasma triglycerides in response to an oral fat load [66]. In vitro studies using Caco- 2 cells showed increased secretion rates of radiolabelled FA into the media from cells transfected with the Thr54 variant relative to cells expressing the predominant Ala54 form of IFABP [69]. In studies comparing jejunal explants [70], it was found that when the tissues were incubated with radiolabeled FA, those containing the Thr-form of IFABP had increased TG synthesis and also increased secretion of TG into the media, relative to those containing the Ala54 allele. It was also observed that chylomicron levels in the media were markedly higher compared to the cells with the Ala-form [70], consistent with the hyperlipidemia observed in human subjects [66]. The physiological effects of this IFABP polymorphism support a role for this protein in intestinal FA metabolism and transport.

\section{LFABP AND IFABP IN INTESTINAL LIPID METABOLISM}

It is unusual that one cell type expresses proteins with identical functions; therefore it is generally believed that LFABP and IFABP have different roles in intestinal lipid metabolism. In the intestine, the hydrolytic products of dietary lipids from the lumen enter the enterocyte from the lumen across the apical side of the cell, while endogenous lipids present in the bloodstream are delivered across the basolateral side [71]. The entry site into the enterocyte markedly impacts the metabolic fate of the lipids: FAs delivered from the apical side of the enterocyte are trafficked towards TG synthesis and chylomicron formation. In contrast, FAs from the bloodstream are more likely to be incorporated into mucosal phospholipids (PL), or oxidized [72-74]. Therefore, the roles of LFABP and IFABP in the delivery of FA from the apical or basolateral sites into the enterocyte have been examined. Alpers et al [34] used an intestinal explant system in which FA were administered either on the apical or basolateral side of the enterocyte to study the roles of IFABP and LFABP in binding of FA. It was observed that LFABP bound more FA than IFABP, regardless of entry site; it is possible that the $n=2$ binding stoichiometry of LFABP may be responsible for these 
observations. Interestingly, IFABP bound more FA after apical administration than basolateral administration, suggesting that this protein is more involved with transport of dietary derived FA, rather than those from the bloodstream [34]. As noted earlier, they also found that both FABPs are localized on the apical side of the enterocytes of fasted rats, but were located throughout the cytoplasm in the fed state [34]. Another study showed that Lcell fibroblasts transfected with IFABP or LFABP had increased incorporation of ${ }^{3}[\mathrm{H}]$-oleic acid uptake into TGs relative to control cells. Cells containing LFABP had increased incorporation into PL, however IFABP expressing cells had increased recovery of the radiolabel in neutral lipids [75].

An important role for the enterocyte FABPs may be in the regulation of the intracellular levels of unbound fatty acids $[4,76,77]$. The intestinal enterocyte has a profusion of free fatty acids being delivered from the diet, and it is known that high levels of free fatty acids in cells can be cytotoxic [78,79]. Therefore, it has been proposed that the FABPs serve a protective function by binding excess cellular FA [76]. In this capacity as well, FABPs may be important for maintaining unbound FA concentrations that are within the functional range of enzymes or receptors. Thus, the FABPs may function to maintain a stable pool of FA and MGs, allowing for steady availability for regulation TG and PL synthesis, chylomicron biogenesis, and cell signaling. In support of this role for the FABPs, enterocyte FABP expression is also upregulated during high-fat feeding, presumably in response to a greater amount of FA delivered to the enterocyte [48,80]. Interestingly, LFABP has been shown to also bind FA acyl CoAs [81]. Thus, IFABP and LFABP could play a role in binding and/or trafficking the large quantity of FA in the cytosol, arriving from the intestinal lumen during the fed state, perhaps to prevent excess accumulation of unbound FA in the cytosol and to maintain homeostatic levels of unbound FA concentrations. For LFABP in particular, maintenance of unbound levels of MGs may also be important. As noted earlier, the enterocyte FABPs may also function by specific protein-protein interactions that deliver ligands to targets including transcription factors or enzymes.

Overall, the coexpression in the enterocyte, plus evidence of differences in transcriptional regulation, ligand binding specificities, and ligand transfer mechanisms, all suggest that IFABP and LFABP have different roles in the intestine. Nevertheless, these functions are not clearly understood. Therefore, in vivo studies using mice null for IFABP and LFABP have been conducted in order to compare the consequences of deleting each of these proteins, so as to further elucidate their functions.

\section{LFABP-I- MICE}

Two laboratories have independently generated individual lines of whole body LFABP-null mice on the C57BL/6 background $[61,82]$. Martin et al. published their first report on the $\mathrm{LFABP}^{-/-}$mouse in 2003, in which there was complete deletion of all 4 exons of the LFABP gene along with the promoter region. These mice were backcrossed 6 times to the C57BL/6N mouse strain [82]. Newberry et al. also published a report in 2003 in which green fluorescent protein was "knocked in" to exons 1 and 2 of the LFABP gene. These mice had a mixed SV129/C57BL/6J background [61], with subsequent studies using mice congenic on the C57BL/6J background [83]. $\mathrm{LFABP}^{-/-}$mice have been shown by both laboratories to 
have defects in hepatic FA oxidation, uptake, and VLDL secretion [43,61,83,84]. However, differences in body weight between the two lines have been reported.

Martin et al. found that male and female $\mathrm{LFABP}^{-/-}$mice were prone to obesity when fed a chow diet, with increases in fat mass relative to WT mice $[85,86]$. When these $\mathrm{LFABP}^{-/-}$ mice were pair-fed a high-fat diet ( $45 \mathrm{kcal} \%$ lard) to ensure equal caloric intakes, females gained more weight relative to WT, but not males [84]. Ad libitum feeding studies by this laboratory showed that a diet containing $25 \mathrm{kcal} \%$ fat promoted increases in fat mass of female $\mathrm{LFABP}^{-/}$mice without apparent changes in food intake [87]. In addition to changes in body weight, they also observed a reduction in ketone production, which suggests a perturbation in lipid oxidation [84,87]. Despite an obese phenotype, both high-fat fed male and female $\mathrm{LFABP}^{-/-}$mice had lower liver weights as a percentage of body weight in pairfed [84], although the opposite was found in ad libitum-fed female mice [87].

As noted above, Newberry et al. have reported several similar observations in the other line of $\mathrm{LFABP}^{-/-}$mice. In particular, they found that the livers of 48-hour fasted $\mathrm{KO}$ mice had lower deposition of TG relative to the WT, suggesting a defect in uptake of fatty acids in this tissue [61]. VLDL secretion and ketone production rates were also lower in these $\mathrm{LFABP}^{-/-}$mice $[61,83,88]$, indicating that transport of lipids out of the liver and into the circulation is also affected by the absence of LFABP. However, the obesity phenotype observed by Martin et al. has not been found by Newberry et al: In several studies, female mice were fed diets containing high amounts of medium chain FA (as hydrogenated coconut oil) and it was observed that $\mathrm{LFABP}^{-/-}$mice were resistant to obesity, gaining less weight and body fat than WT mice $[83,89-91]$. The resistance of this line of $\mathrm{LFABP}^{-/-}$mice to diet-induced obesity has been shown primarily, although not exclusively, on a high-fat diet containing hydrogenated coconut oil, which is likely to be deficient in the essential fatty acids linoleate and linolenate [92]. They also observed that female $\mathrm{LFABP}^{-/-}$mice were resistant to obesity and hepatic steatosis when fed a Western diet containing $41 \mathrm{kcal} \%$ butter fat, a source which is rich in long chain FA $[83,88]$, however, no differences in body weight were found between these $\mathrm{LFABP}^{-/-}$and WT mice when females were fed diets containing high levels of polyunsaturated FA (41 kcal\% safflower oil), or when fed diets containing high levels of trans unsaturated fats $[89,93]$. Differences in results between the $\mathrm{LFABP}^{-/-}$ strains, and the above mentioned differences in one strain in response to different fat sources, may be attributable to background strain differences (C57BL/6J versus C57BL/6N), the methods of gene ablation [76], the dietary protocols used, and/or environmental effects from differences in the animal facilities that could affect susceptibility to obesity, such as the resident gut microbiota [94].

\section{IFABP-/- MICE}

One line of IFABP ${ }^{-/}$mice has been generated, which were backcrossed for 6 generations onto the C57BL/6J background by Vassileva et al. [62]. Male mice fed diets with $35 \mathrm{kcal} \%$ fat as coconut oil and $1.25 \%$ cholesterol had an increase in body weight relative to wild-type mice (WT), and also developed fatty livers. By contrast, female mice gained less weight than WT and did not exhibit any changes in hepatic lipid accumulation [62]. It was further found that aged (30-40 week old) male IFABP ${ }^{-/-}$mice fed $41 \mathrm{kcal} \%$ fat diets containing 
beef tallow or safflower oil for 14 days had higher body weights relative to WT mice, and greater liver TG accumulation [95]. Since LFABP and IFABP are coexpressed in the enterocyte, it was hypothesized that each protein might compensate for the other, but it was found that LFABP mRNA expression was not increased in the intestinal mucosa of $\mathrm{IFABP}^{-/-}$mice [62]. Newberry et al also measured IFABP mRNA in $\mathrm{LFABP}^{-/-}$mice and found that there was no difference in IFABP levels in the intestinal enterocytes of $\mathrm{LFABP}^{-/-}$ mice relative WT, suggesting that there is no compensatory upregulation [61].

\section{DIRECT COMPARISON BETWEEN LFABP-/- AND IFABP-/- MICE}

To further investigate and systematically address the individual functions of these proteins, Lagakos et al. conducted comparative studies using both LFABP and IFABP-null mice. LFABP-null mice which were initially generated by Martin et al. [82] were used. These mice, which as noted above had been backcrossed for 6 generations onto the C57BL/6N strain, were backcrossed for another 6 generations onto the C57BL/6J strain [44]. IFABP ${ }^{-/-}$ mice were bred from those used originally by Vassileva et al. without further backcrossing [62]. No evidence of compensatory upregulation of IFABP was found in intestinal mucosa in response to ablation of LFABP, and vice versa [44]. No differences in body weight were observed in chow-fed IFABP-null or LFABP-null male mice relative to WT mice [44], however several phenotypic changes were noted: In response to fasting, IFABP ${ }^{-/-}$mice lost more fat mass compared to WT mice, while $\mathrm{LFABP}^{-/-}$mice lost less fat-free mass than WT [44]. Intraduodenal administration of $\left[{ }^{14} \mathrm{C}\right] \mathrm{FA}$ in $\mathrm{IFABP}^{-/-}$mice showed an increase in recovery of radiolabel in PL in the mucosa relative to WT, resulting in a decrease in the TG/PL ratio, suggesting that IFABP directs FA towards synthesis of TG and away from PL. For the $\mathrm{LFABP}^{-/-}$mice, no effects on $\left[{ }^{14} \mathrm{C}\right] \mathrm{FA}$ metabolism were found, however, the intraduodenal delivery of $\left[{ }^{3} \mathrm{H}\right]$ monoolein via the duodenum resulted in increased incorporation of the label in mucosal PL, MG, and DG, while recovery of TG was decreased in $\mathrm{LFABP}^{-/-}$mice relative to WT, suggesting that LFABP is involved in the transport of MG away from PL synthesis and toward TG synthesis. LFABP ablation also resulted in a reduction in mucosal oxidation of intraduodenally administered oleate. These results suggest that LFABP is involved with trafficking FA towards oxidative pathways and trafficking of MG towards TG, rather than PL [44].

Lagakos et al. did not find robust changes in whole body phenotype between $\mathrm{LFABP}^{-/-}$and IFABP $^{-/-}$mice fed a low fat chow diet, therefore high-fat feeding studies were conducted to determine whether a lipid overload to the enterocyte might reveal more profound changes in the phenotypes of these mice. Thus, a direct comparison was undertaken in which LFABPnull and IFABP-null mice were fed high-fat diets containing $45 \mathrm{kcal} \%$ long chain saturated FA (cocoa butter) or unsaturated FA (high oleic safflower oil). The results revealed dramatically different phenotypic responses to the high-fat diets: $\mathrm{LFABP}^{-/-}$mice gained more weight and fat mass relative to WT mice, but $\mathrm{IFABP}^{-/-}$mice were lean, with lower body weight and body fat mass relative to WT (Figure 1) [45]. LFABP ${ }^{-/}$mice fed high-fat diets had lower respiratory exchange ratios (RER) than WT mice, suggesting that these mice preferentially oxidize fat as an energy source. In contrast, high-fat fed IFABP ${ }^{-/-}$mice had higher RERs, indicating that these mice are primarily utilizing carbohydrates as an energy source. Importantly, fecal lipids of $\mathrm{IFABP}^{-/-}$or $\mathrm{LFABP}^{-/-}$mice fed low-fat or high-fat diets 
did not differ from WT, in agreement with other reports $[44,45,62,88,89]$, indicating that even on high-fat diets, lipid malabsorption does not occur.

It was also found that $\mathrm{LFABP}^{-/-}$mice consumed more calories than WT during high saturated fat diet feeding. As noted earlier, recent findings have shown that FABPs are carriers of anandamide (AEA) [11], an endocannabinoid that is a ligand for the CB1 receptor [11]. Binding of $A E A$ to $\mathrm{CB}_{1}$ causes an acute increase in food intake, and interestingly, high-fat fed $\mathrm{LFABP}^{-/-}$mice had elevated levels of AEA in the intestinal mucosa [45].

Additionally, the $\mathrm{LFABP}^{-/-}$mice were found to have increased levels of 2arachidonoylglycerol, an MG that is an endogenous endocannabinoid that binds to cannabinoid receptors and also promotes an increase in food intake [96]. As mentioned above, it has been recently shown that LFABP binds MGs [16]. While the roles of intestinal endocannabinoids in the regulation of food intake are not clear, these observation suggest that LFABP may play a role in regulation of these signaling lipids to maintain whole body energy homeostasis [97].

As with the chow-fed mice, there was a decrease in incorporation of radiolabeled FA into TG relative to PL in intestinal mucosa of high-fat fed IFABP ${ }^{-/-}$mice, and the $\mathrm{LFABP}^{-/-}$ mice had reduced radiolabeled MG incorporation in TG relative to PL, providing further evidence of the importance of IFABP in FA trafficking toward TG, and of LFABP in MG trafficking in the enterocyte $[16,98]$. In addition, the high-fat fed LFABP-null mice had reduced oxidation of $\left[{ }^{14} \mathrm{C}\right] \mathrm{FA}$ in the intestine, in concordance with results in the chow-fed mice $[44,45]$. Interestingly, these changes in metabolism for $\mathrm{IFABP}^{-/-}$and $\mathrm{LFABP}^{-/-}$mice occurred without notable differences in gene expression of key enzymes involved with intestinal lipid metabolism, suggesting that in the intestine these alterations may be a result of trafficking and/or targeting defects rather than transcriptional regulation [44,45]. Table 1 presents a comparative summary of the effects of whole body LFABP vs. IFABP deletion in mice.

\section{SUMMARY AND PERSPECTIVE}

Perhaps surprisingly, deletion of either LFABP or IFABP does not result in dietary lipid malabsorption, even with chronic high-fat feeding. Furthermore, and more remarkably, preliminary studies of an LFABP/IFABP double-knockout mouse show no increase in fecal fat on a high-fat diet (AM Gajda and J Storch, unpublished results). Ablation of each of these genes results in changes in intestinal lipid metabolism, as shown schematically in Figure 2 . These changes, which are relatively modest, nevertheless, result in profound and unanticipated changes in whole body energy homeostasis. These effects of LFABP and IFABP deletion support the growing understanding of the link between intestinal lipid metabolism and transport, and systemic energy balance. Certainly, the markedly divergent phenotypes observed in $\mathrm{LFABP}^{-/}$and $\mathrm{IFABP}^{-/-}$mice provide unequivocal evidence for their independent functions. The large effects at the whole body level, coupled with an absence of frank dietary lipid malabsorption, points toward alternative functions for each of these proteins; it is proposed that they may act as lipid sensors, serving both to maintain homeostatic levels of unbound fatty acids and monoacylglycerols for utilization by target proteins, and perhaps to directly deliver their ligands to specific targets as well, thereby 
acting in a signaling capacity that ultimately transmits the presence and/or level of incoming ligands/nutrients to the rest of the body. Overall, the in vitro differences between the proteins, and the recent comparative in vivo studies, clearly support the idea that IFABP and LFABP play different roles in the enterocyte, which lead to differential downstream effects on whole body energy balance.

\section{Acknowledgments}

This work was supported, in whole or in part, by National Institutes of Health Grant DK-38389 from NIDDK. This work was also supported by funds from the New Jersey Agricultural Experiment Station.

\section{Abbreviations}

2-AG 2-arachidonoylglycerol

AEA arachidinoylethanolamide

$\mathbf{C B}_{1} \quad$ cannabinoid receptor 1

$\mathbf{C B}_{2} \quad$ cannabinoid receptor 2

FA Fatty acid

FXR farnesoid X receptor

IFABP Intestinal-fatty acid binding protein

ILBP Ileal lipid binding protein

KO knockout

LFABP Liver-fatty acid binding protein

MG monoacylglycerol

NAE n-acylethanolamine

NAPE n-acylphosphatidylethanolamines

PPAR peroxisome proliferator-activated receptor

PCTV pre-chylomicron transport vesicle

PL phospholipid

RER respiratory exchange ratio

TG triacyglycerol

VLDL very-low density lipoproteins

\section{References}

1. Ockner RK, Manning JA. Fatty acid-binding protein in small intestine. Identification, isolation, and evidence for its role in cellular fatty acid transport. J Clin Invest. 1974; 54:326-38. [PubMed: 4211161]

2. Mishkin S, Stein L, Gatmaitan Z, Arias IM. The binding of fatty acids to cytoplasmic proteins: binding to $\mathrm{Z}$ protein in liver and other tissues of the rat. Biochem Biophys Res Commun. 1972; 47:997-1003. [PubMed: 5029869] 
3. Storch J, Corsico B. The emerging functions and mechanisms of mammalian fatty acid-binding proteins. Annu Rev Nutr. 2008; 28:73-95. [PubMed: 18435590]

4. Haunerland NH, Spener F. Fatty acid-binding proteins--insights from genetic manipulations. Prog Lipid Res. 2004; 43:328-49. [PubMed: 15234551]

5. Hertzel AV, Bernlohr DA. The mammalian fatty acid-binding protein multigene family: molecular and genetic insights into function. Trends Endocrinol Metab. 2000; 11:175-80. [PubMed: 10856918]

6. Coe NR, Bernlohr DA. Physiological properties and functions of intracellular fatty acid-binding proteins. Biochim Biophys Acta. 1998; 1391:287-306. [PubMed: 9555061]

7. Corsico B, Liou HL, Storch J. The alpha-helical domain of liver fatty acid binding protein is responsible for the diffusion-mediated transfer of fatty acids to phospholipid membranes. Biochemistry. 2004; 43:3600-7. [PubMed: 15035630]

8. Corsico B, Cistola DP, Frieden C, Storch J. The helical domain of intestinal fatty acid binding protein is critical for collisional transfer of fatty acids to phospholipid membranes. Proc Natl Acad Sci U S A. 1998; 95:12174-8. [PubMed: 9770459]

9. Chmurzyńska A. The multigene family of fatty acid-binding proteins (FABPs): function, structure and polymorphism. J Appl Genet. 2006; 47:39-48. [PubMed: 16424607]

10. Storch J, Thumser AE. Tissue-specific functions in the fatty acid-binding protein family. J Biol Chem. 2010; 285:32679-83. [PubMed: 20716527]

11. Kaczocha M, Glaser ST, Deutsch DG. Identification of intracellular carriers for the endocannabinoid anandamide. Proc Natl Acad Sci U S A. 2009; 106:6375-80. [PubMed: 19307565]

12. Piomelli D. More surprises lying ahead. The endocannabinoids keep us guessing. Neuropharmacology. 2013:1-7.

13. Devane WA, Hanus L, Breuer A, Pertwee RG, Stevenson LA, Griffin G, et al. Isolation and structure of a brain constituent that binds to the cannabinoid receptor. Science. 1992; 258:1946-9. [PubMed: 1470919]

14. Sugiura T, Kodaka T, Nakane S, Miyashita T, Kondo S, Suhara Y, et al. Evidence that the cannabinoid CB1 receptor is a 2-arachidonoylglycerol receptor. Structure-activity relationship of 2-arachidonoylglycerol, ether-linked analogues, and related compounds. J Biol Chem. 1999; 274:2794-801. [PubMed: 9915812]

15. Jung KM, Clapper JR, Fu J, D’Agostino G, Guijarro A, Thongkham D, et al. 2arachidonoylglycerol signaling in forebrain regulates systemic energy metabolism. Cell Metab. 2012; 15:299-310. [PubMed: 22405068]

16. Lagakos WS, Guan X, Ho SY, Sawicki LR, Corsico B, Kodukula S, et al. Liver Fatty Acid-binding Protein Binds Monoacylglycerol in Vitro and in Mouse Liver Cytosol. J Biol Chem. 2013; 288:19805-15. [PubMed: 23658011]

17. Caspary WF. Physiology and pathophysiology of intestinal absorption. Am J Clin Nutr. 1992; 55:299S-308S. [PubMed: 1728844]

18. Guilmeau S, Niot I, Laigneau JP, Devaud H, Petit V, Brousse N, et al. Decreased expression of Intestinal I- and L-FABP levels in rare human genetic lipid malabsorption syndromes. Histochem Cell Biol. 2007; 128:115-23. [PubMed: 17605029]

19. Levy E, Menard D, Delvin E, Montoudis A, Beaulieu JF, Mailhot G, et al. Localization, function and regulation of the two intestinal fatty acid-binding protein types. Histochem Cell Biol. 2009; 132:351-67. [PubMed: 19499240]

20. Pelsers MMAL, Namiot Z, Kisielewski W, Namiot A, Januszkiewicz M, Hermens WT, et al. Intestinal-type and liver-type fatty acid-binding protein in the intestine. Tissue distribution and clinical utility. Clin Biochem. 2003; 36:529-35. [PubMed: 14563446]

21. Bass NM, Manning JA, Ockner RK, Gordon JI, Seetharam S, Alpers DH. Regulation of the biosynthesis of two distinct fatty acid-binding proteins in rat liver and intestine. Influences of sex difference and of clofibrate. J Biol Chem. 1985; 260:1432-6. [PubMed: 3968078]

22. Zimmerman AW, van Moerkerk HT, Veerkamp JH. Ligand specificity and conformational stability of human fatty acid-binding proteins. Int J Biochem Cell Biol. 2001; 33:865-76. [PubMed: 11461829] 
23. Fujita M, Fujii H, Kanda T, Sato E, Hatakeyama K, Ono T. Molecular cloning, expression, and characterization of a human intestinal 15-kDa protein. Eur J Biochem. 1995; 233:406-13. [PubMed: 7588781]

24. Miller KR, Cistola DP. Titration calorimetry as a binding assay for lipid-binding proteins. Mol Cell Biochem. 1993; 123:29-37. [PubMed: 8232265]

25. Ono T. Studies of the FABP family: a retrospective. Mol Cell Biochem. 2005; 277:1-6. [PubMed: 16132708]

26. Grober J. Identification of a bile acid-responsive element in the human ileal bile acid-binding protein gene. Involvement of the Farnesoid X receptor/9-cis-retinoic acid receptor heterodimer. J Biol Chem. 1999; 274:29749-29754. [PubMed: 10514450]

27. Hwang ST, Urizar NL, Moore DD, Henning SJ. Bile acids regulate the ontogenic expression of ileal bile acid binding protein in the rat via the farnesoid X receptor. Gastroenterology. 2002; 122:1483-1492. [PubMed: 11984532]

28. Praslickova D, Torchia EC, Sugiyama MG, Magrane EJ, Zwicker BL, Kolodzieyski L, et al. The ileal lipid binding protein is required for efficient absorption and transport of bile acids in the distal portion of the murine small intestine. PLoS One. 2012; 7:e50810. [PubMed: 23251388]

29. Agellon LB, Toth MJ, Thomson ABR. Intracellular lipid binding proteins of the small intestine. Mol Cell Biochem. 2002; 239:79-82. [PubMed: 12479571]

30. Richieri GV, Ogata RT, Zimmerman AW, Veerkamp JH, Kleinfeld AM. Fatty acid binding proteins from different tissues show distinct patterns of fatty acid interactions. Biochemistry. 2000; 39:7197-204. [PubMed: 10852718]

31. Richieri GV, Ogata RT, Kleinfeld aM. Equilibrium constants for the binding of fatty acids with fatty acid-binding proteins from adipocyte, intestine, heart, and liver measured with the fluorescent probe ADIFAB. J Biol Chem. 1994; 269:23918-30. [PubMed: 7929039]

32. Storch J, Veerkamp JH, Hsu KT. Similar mechanisms of fatty acid transfer from human anal rodent fatty acid-binding proteins to membranes: liver, intestine, heart muscle, and adipose tissue FABPs. Mol Cell Biochem. 2002; 239:25-33. [PubMed: 12479565]

33. Hsu KT, Storch J. Fatty acid transfer from liver and intestinal fatty acid-binding proteins to membranes occurs by different mechanisms. J Biol Chem. 1996; 271:13317-23. [PubMed: 8662836]

34. Alpers DH, Bass NM, Engle MJ, DeSchryver-Kecskemeti K. Intestinal fatty acid binding protein may favor differential apical fatty acid binding in the intestine. Biochim Biophys Acta. 2000; 1483:352-62. [PubMed: 10666570]

35. Siddiqi S, Saleem U, Abumrad NA, Davidson NO, Storch J, Siddiqi SA, et al. A novel multiprotein complex is required to generate the prechylomicron transport vesicle from intestinal ER. J Lipid Res. 2010; 51:1918-28. [PubMed: 20237389]

36. Issemann I, Prince R, Tugwood J, Green S. A role for fatty acids and liver fatty acid binding protein in peroxisome proliferation? Biochem Soc Trans. 1992; 20:824-7. [PubMed: 1487072]

37. Nakamura MT, Yudell BE, Loor JJ. Regulation of energy metabolism by long-chain fatty acids. Prog Lipid Res. 2014; 53:124-44. [PubMed: 24362249]

38. Mallordy A, Poirier H, Besnard P, Niot I, Carlier H. Evidence for transcriptional induction of the liver fatty-acid-binding-protein gene by bezafibrate in the small intestine. Eur J Biochem. 1995; 227:801-7. [PubMed: 7867641]

39. Babeu JP, Boudreau F. Hepatocyte nuclear factor 4-alpha involvement in liver and intestinal inflammatory networks. World J Gastroenterol. 2014; 20:22-30. [PubMed: 24415854]

40. McIntosh AL, Atshaves BP, Hostetler Ha, Huang H, Davis J, Lyuksyutova OI, et al. Liver type fatty acid binding protein (L-FABP) gene ablation reduces nuclear ligand distribution and peroxisome proliferator-activated receptor-alpha activity in cultured primary hepatocytes. Arch Biochem Biophys. 2009; 485:160-73. [PubMed: 19285478]

41. Hostetler HA, McIntosh AL, Atshaves BP, Storey SM, Payne HR, Kier AB, et al. LFABP directly interacts with PPARalpha in cultured primary hepatocytes. J Lipid Res. 2009; 50:1663-75. [PubMed: 19289416] 
42. McIntosh AL, Petrescu AD, Hostetler HA, Kier AB, Schroeder F. Liver-type fatty acid binding protein interacts with hepatocyte nuclear factor 4a. FEBS Lett. 2013; 587:3787-91. [PubMed: 24140341]

43. Erol E, Kumar LS, Cline GW, Shulman GI, Kelly DP, Binas B. Liver fatty acid-binding protein is required for high rates of hepatic fatty acid oxidation but not for the action of PPAR-alpha in fasting mice. FASEB J. 2004; 18:347-9. [PubMed: 14656998]

44. Lagakos WS, Gajda AM, Agellon L, Binas B, Choi V, Mandap B, et al. Different functions of intestinal and liver-type fatty acid-binding proteins in intestine and in whole body energy homeostasis. Am J Physiol Gastrointest Liver Physiol. 2011; 300:G803-14. [PubMed: 21350192]

45. Gajda AM, Zhou YX, Agellon LB, Fried SK, Kodukula S, Fortson WM, et al. Direct Comparison of Mice Null for Liver- or Intestinal Fatty Acid Binding Proteins Reveals Highly Divergent Phenotypic Responses to High-Fat Feeding. J Biol Chem. 2013; 288:30330-30344. [PubMed: 23990461]

46. Besnard P, Mallordy a, Carlier H. Transcriptional induction of the fatty acid binding protein gene in mouse liver by bezafibrate. FEBS Lett. 1993; 327:219-23. [PubMed: 8335112]

47. Poirier H, Niot I, Degrace P, Monnot MC, Bernard A, Besnard P, et al. Fatty acid regulation of fatty acid-binding protein expression in the small intestine. Am J Physiol - Gastrointest Liver Physiol. 1997; 273:G289-G295.

48. Malewiak M, Bass N, Griglio S, Ockner RK. Influence of genetic obesity and of fat-feeding on hepatic FABP concentration and activity. Int J Obes. 1988; 12:543-546. [PubMed: 3235271]

49. Petit V, Arnould L, Martin P, Monnot MC, Pineau T, Besnard P, et al. Chronic high-fat diet affects intestinal fat absorption and postprandial triglyceride levels in the mouse. J Lipid Res. 2007; 48:278-87. [PubMed: 17114807]

50. Ockner RK, Burnett DA, Lysenko N, Manning JA. Sex differences in long chain fatty acid utilization and fatty acid binding protein concentration in rat liver. J Clin Invest. 1979; 64:172-81. [PubMed: 447853]

51. Robitaille J, Brouillette C, Lemieux S, Perusse L, Gaudet D, Vohl MC. Plasma concentrations of apolipoprotein B are modulated by a gene--diet interaction effect between the LFABP T94A polymorphism and dietary fat intake in French-Canadian men. Mol Genet Metab. 2004; 82:296303. [PubMed: 15308127]

52. Brouillette C, Bosse Y, Perusse L, Gaudet D, Vohl MC. Effect of liver fatty acid binding protein (FABP) T94A missense mutation on plasma lipoprotein responsiveness to treatment with fenofibrate. J Hum Genet. 2004; 49:424-32. [PubMed: 15249972]

53. Fisher E, Weikert C, Klapper M, Lindner I, Mohlig M, Spranger J, et al. L-FABP T94A is associated with fasting triglycerides and LDL-cholesterol in women. Mol Genet Metab. 2007; 91:278-84. [PubMed: 17485234]

54. Gao N, Qu X, Yan J, Huang Q, Yuan HY, Ouyang DS. L-FABP T94A decreased fatty acid uptake and altered hepatic triglyceride and cholesterol accumulation in Chang liver cells stably transfected with L-FABP. Mol Cell Biochem. 2010; 345:207-14. [PubMed: 20721681]

55. Martin GG, McIntosh AL, Huang H, Gupta S, Atshaves BP, Landrock KK, et al. The human liver fatty acid binding protein T94A variant alters the structure, stability, and interaction with fibrates. Biochemistry. 2013; 52:9347-57. [PubMed: 24299557]

56. Sacchettini JC, Hauft SM, Van Camp SL, Cistola DP, Gordon JI. Developmental and structural studies of an intracellular lipid binding protein expressed in the ileal epithelium. J Biol Chem. 1990; 265:19199-207. [PubMed: 1699943]

57. Neeli I, Siddiqi Sa, Siddiqi S, Mahan J, Lagakos WS, Binas B, et al. Liver fatty acid-binding protein initiates budding of pre-chylomicron transport vesicles from intestinal endoplasmic reticulum. J Biol Chem. 2007; 282:17974-84. [PubMed: 17449472]

58. Lowe JB, Sacchettini JC, Laposata M, McQuillan JJ, Gordon JI. Expression of rat intestinal fatty acid-binding protein in Escherichia coli. Purification and comparison of ligand binding characteristics with that of Escherichia coli-derived rat liver fatty acid-binding protein. J Biol Chem. 1987; 262:5931-7. [PubMed: 3553183] 
59. Franchini GR, Storch J, Corsico B. The integrity of the alpha-helical domain of intestinal fatty acid binding protein is essential for the collision-mediated transfer of fatty acids to phospholipid membranes. Biochim Biophys Acta. 2008; 1781:192-9. [PubMed: 18284926]

60. Hallden G, Aponte GW. Evidence for a role of the gut hormone PYY in the regulation of intestinal fatty acid-binding protein transcripts in differentiated subpopulations of intestinal epithelial cell hybrids. J Biol Chem. 1997; 272:12591-600. [PubMed: 9139712]

61. Newberry EP, Xie Y, Kennedy S, Han X, Buhman KK, Luo J, et al. Decreased hepatic triglyceride accumulation and altered fatty acid uptake in mice with deletion of the liver fatty acid-binding protein gene. J Biol Chem. 2003; 278:51664-72. [PubMed: 14534295]

62. Vassileva G, Huwyler L, Poirier K, Agellon LB, Toth MJ. The intestinal fatty acid binding protein is not essential for dietary fat absorption in mice. FASEB J. 2000; 14:2040-6. [PubMed: 11023988]

63. Besnard P, Niot I, Poirier H, Clement L, Bernard A. New insights into the fatty acid-binding protein (FABP) family in the small intestine. Mol Cell Biochem. 2002; 239:139-47. [PubMed: 12479579]

64. Baier LJ, Sacchettini JC, Knowler WC, Eads J, Paolisso G, Tataranni Pa, et al. An amino acid substitution in the human intestinal fatty acid binding protein is associated with increased fatty acid binding, increased fat oxidation, and insulin resistance. J Clin Invest. 1995; 95:1281-7. [PubMed: 7883976]

65. Pratley RE, Baier L, Pan DA, Salbe AD, Storlien L, Ravussin E, et al. Effects of an Ala54Thr polymorphism in the intestinal fatty acid-binding protein on responses to dietary fat in humans. $\mathrm{J}$ Lipid Res. 2000; 41:2002-8. [PubMed: 11108733]

66. Georgopoulos A, Aras O, Tsai MY. Codon-54 polymorphism of the fatty acid-binding protein 2 gene is associated with elevation of fasting and postprandial triglyceride in type 2 diabetes. J Clin Endocrinol Metab. 2000; 85:3155-60. [PubMed: 10999802]

67. Agren JJ, Valve R, Vidgren H, Laakso M, Uusitupa M. Postprandial lipemic response is modified by the polymorphism at codon 54 of the fatty acid-binding protein 2 gene. Arterioscler Thromb Vasc Biol. 1998; 18:1606-10. [PubMed: 9763533]

68. Yamada K, Yuan X, Ishiyama S, Koyama K, Ichikawa F, Koyanagi a, et al. Association between Ala54Thr substitution of the fatty acid-binding protein 2 gene with insulin resistance and intraabdominal fat thickness in Japanese men. Diabetologia. 1997; 40:706-10. [PubMed: 9222651]

69. Baier LJ, Bogardus C, Sacchettini JC. A polymorphism in the human intestinal fatty acid binding protein alters fatty acid transport across Caco-2 cells. J Biol Chem. 1996; 271:10892-6. [PubMed: 8631905]

70. Levy E, Menard D, Delvin E, Stan S, Mitchell G, Lambert M, et al. The polymorphism at codon 54 of the FABP2 gene increases fat absorption in human intestinal explants. J Biol Chem. 2001; 276:39679-84. [PubMed: 11487582]

71. Porter CJH, Trevaskis NL, Charman WN. Lipids and lipid-based formulations: optimizing the oral delivery of lipophilic drugs. Nat Rev Drug Discov. 2007; 6:231-48. [PubMed: 17330072]

72. Mansbach CM, Dowell RF. Uptake and metabolism of circulating fatty acids by rat intestine. Am J Physiol. 1982; 263:G927-33. [PubMed: 1476200]

73. Storch J, Zhou YX, Lagakos WS. Metabolism of apical versus basolateral sn-2- monoacylglycerol and fatty acids in rodent small intestine. J Lipid Res. 2008; 49:1762-9. [PubMed: 18421071]

74. Gangl A, Ockner RK. Intestinal metabolism of plasma free fatty acids. Intracellular compartmentation and mechanisms of control. J Clin Invest. 1975; 55:803-13. [PubMed: 1120783]

75. Prows D, Murphy E, Schroeder F. Intestinal and liver fatty acid binding proteins differentially affect fatty acid uptake and esterification in L-cells. Lipids. 1995; 30:907-910. [PubMed: 8538377]

76. Atshaves BP, Martin GG, Hostetler HA, McIntosh AL, Kier AB, Schroeder F. Liver fatty acidbinding protein and obesity. J Nutr Biochem. 2010; 21:1015-32. [PubMed: 20537520]

77. Veerkamp JH, van Kuppevelt THMSM, Maatman RGHJ, Prinsen CFM. Structural and functional aspects of cytosolic fatty acid-binding proteins, Prostaglandins. Leukot Essent Fat Acids. 1993; 49:887-906. 
78. Kazantzis M, Stahl A. Fatty acid transport proteins, implications in physiology and disease. Biochim Biophys Acta. 2012; 1821:852-7. [PubMed: 21979150]

79. Listenberger LL, Ory DS, Schaffer JE. Palmitate-induced apoptosis can occur through a ceramideindependent pathway. J Biol Chem. 2001; 276:14890-5. [PubMed: 11278654]

80. Bass N. Fatty acid-protein expression in the liver: its regulation and relationship to the zonation of fatty acid metabolism. Mol Cell Biochem. 1990; 98:167-176. [PubMed: 2266958]

81. Hubbell T, Behnke WD, Woodford JK, Schroeder F. Recombinant liver fatty acid binding protein interacts with fatty acyl-coenzyme A. Biochemistry. 1994; 33:3327-34. [PubMed: 8136369]

82. Martin GG, Danneberg H, Kumar LS, Atshaves BP, Erol E, Bader M, et al. Decreased liver fatty acid binding capacity and altered liver lipid distribution in mice lacking the liver fatty acid-binding protein gene. J Biol Chem. 2003; 278:21429-38. [PubMed: 12670956]

83. Newberry EP, Xie Y, Kennedy SM, Luo J, Davidson NO. Protection against Western diet-induced obesity and hepatic steatosis in liver fatty acid-binding protein knockout mice. Hepatology. 2006; 44:1191-205. [PubMed: 17058218]

84. Atshaves BP, McIntosh AL, Storey SM, Landrock KK, Kier AB, Schroeder F. High dietary fat exacerbates weight gain and obesity in female liver fatty acid binding protein gene-ablated mice. Lipids. 2010; 45:97-110. [PubMed: 20035485]

85. Martin GG, Atshaves BP, McIntosh AL, Mackie JT, Kier AB, Schroeder F. Liver fatty acidbinding protein gene-ablated female mice exhibit increased age-dependent obesity. J Nutr. 2008; 138:1859-65. [PubMed: 18806093]

86. Martin GG, Atshaves BP, McIntosh AL, Payne HR, Mackie JT, Kier AB, et al. Liver fatty acid binding protein gene ablation enhances age-dependent weight gain in male mice. Mol Cell Biochem. 2009; 324:101-15. [PubMed: 19104910]

87. McIntosh AL, Atshaves BP, Landrock D, Landrock KK, Martin GG, Storey SM, et al. Liver fatty acid binding protein gene-ablation exacerbates weight gain in high-fat fed female mice. Lipids. 2013; 48:435-48. [PubMed: 23539345]

88. Newberry EP, Kennedy SM, Xie Y, Luo J, Davidson NO. Diet-induced alterations in intestinal and extrahepatic lipid metabolism in liver fatty acid binding protein knockout mice. Mol Cell Biochem. 2009; 326:79-86. [PubMed: 19116776]

89. Newberry EP, Kennedy SM, Xie Y, Sternard BT, Luo J, Davidson NO. Diet-induced obesity and hepatic steatosis in L-Fabp/mice is abrogated with SF, but not PUFA, feeding and attenuated after cholesterol supplementation. Am J Physiol Gastrointest Liver Physiol. 2008; 294:G307-14. [PubMed: 18032478]

90. Newberry EP, Davidson NO. Liver Fatty Acid Binding Protein (L-FABP) as a Target for the Prevention of High Fat Diet Induced Obesity and Hepatic Steatosis. Immunol Endocr Metab Agents - Med Chem (Formerly Curr Med Chem - Immunol Endocr Metab Agents). 2009; 9:30-37.

91. Newberry EP, Kennedy SM, Xie Y, Luo J, Crooke RM, Graham MJ, et al. Decreased body weight and hepatic steatosis with altered fatty acid ethanolamide metabolism in aged L-Fabp -/- mice. J Lipid Res. 2012; 53:744-54. [PubMed: 22327204]

92. Williams MA, Tamai KT, Hincenbergs I, McIntosh DJ. Hydrogenated coconut oil and tissue fatty acids in EFA-depleted and EFA-supplemented rats. J Nutr. 1972; 102:847-55. [PubMed: 5034372]

93. Chen A, Tang Y, Davis V, Hsu FF, Kennedy SM, Song H, et al. Liver fatty acid binding protein (L-Fabp) modulates murine stellate cell activation and diet-induced nonalcoholic fatty liver disease. Hepatology. 2013; 57:2202-12. [PubMed: 23401290]

94. Kahn, CR.; Bezy, O.; Usar, S.; Griffin, NW.; Gordon, JI. Diabetes and Obesity-Nature vs Nurture. Keystone Symp. Diabetes-New Insights into Mech. Dis. Its Treat., Keystone Symposia; Keystone, CO. n.d; p. 42

95. Agellon LB, Drozdowski L, Li L, Iordache C, Luong L, Clandinin MT, et al. Loss of intestinal fatty acid binding protein increases the susceptibility of male mice to high fat diet-induced fatty liver. Biochim Biophys Acta. 2007; 1771:1283-8. [PubMed: 17905650]

96. Stella N, Schweitzer P, Piomelli D. A second endogenous cannabinoid that modulates long-term potentiation. Nature. 1997; 388:773-8. [PubMed: 9285589] 
97. Chon SH, Douglass JD, Zhou YX, Malik N, Dixon JL, Brinker A, et al. Over-expression of monoacylglycerol lipase (MGL) in small intestine alters endocannabinoid levels and whole body energy balance, resulting in obesity. PLoS One. 2012; 7:e43962. [PubMed: 22937137]

98. Storch J. Diversity of fatty acid-binding protein structure and function: studies with fluorescent ligands. Mol Cell Biochem. 1993; 123:45-53. [PubMed: 8232268]

99. Niot I, Poirier H, Tran TTT, Besnard P. Intestinal absorption of long-chain fatty acids: Evidence and uncertainties. Prog Lipid Res. 2009; 48:101-115. [PubMed: 19280719] 

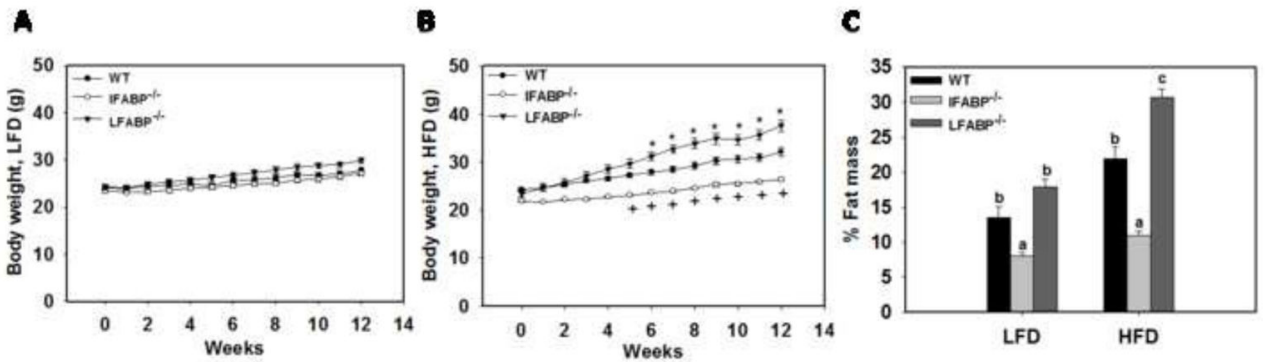

Figure 1. Body weight and composition for WT, IFABP $^{-/-}$, or $\mathrm{LFABP}^{-/-}$mice fed a low-fat (LFD) or high-fat (HFD) diet

A. Body weights on LFD $(n=15-16)$. B. Body weights on HFD $(n=13-14)$. C. Percent fat mass of mice fed LFD or HFD $(\mathrm{n}=12-16)$. $A-B$, data are mean \pm S.E., analyzed using twoway ANOVA using repeated measures with post hoc Tukey's test (genotype $\times$ time) $*, p<$ 0.05 for $\mathrm{LFABP}^{-/-}$versus $\mathrm{WT} ;+, p<0.05$ for $\mathrm{IFABP}^{-/-}$versus $\mathrm{WT}$. $C$, data are mean \pm S.E., analyzed using one-way ANOVA with a Tukey's post hoc test. Results with different letters within diet treatment are significantly different $(p<0.05)$. This figure was originally published in The Journal of Biological Chemistry. Angela M. Gajda, Yin Xiu Zhou, Luis B. Agellon, Susan K. Fried, Sarala Kodukula, Walter Fortson, Khamoshi Patel, and Judith Storch. Direct Comparison of Mice Null for Liver or Intestinal Fatty Acid-Binding Proteins Reveals Highly Divergent Phenotypic Responses to High Fat Feeding. Journal of Biological Chemistry 2013; 288:30330-30344. (C) The American Society for Biochemistry and Molecular Biology. 


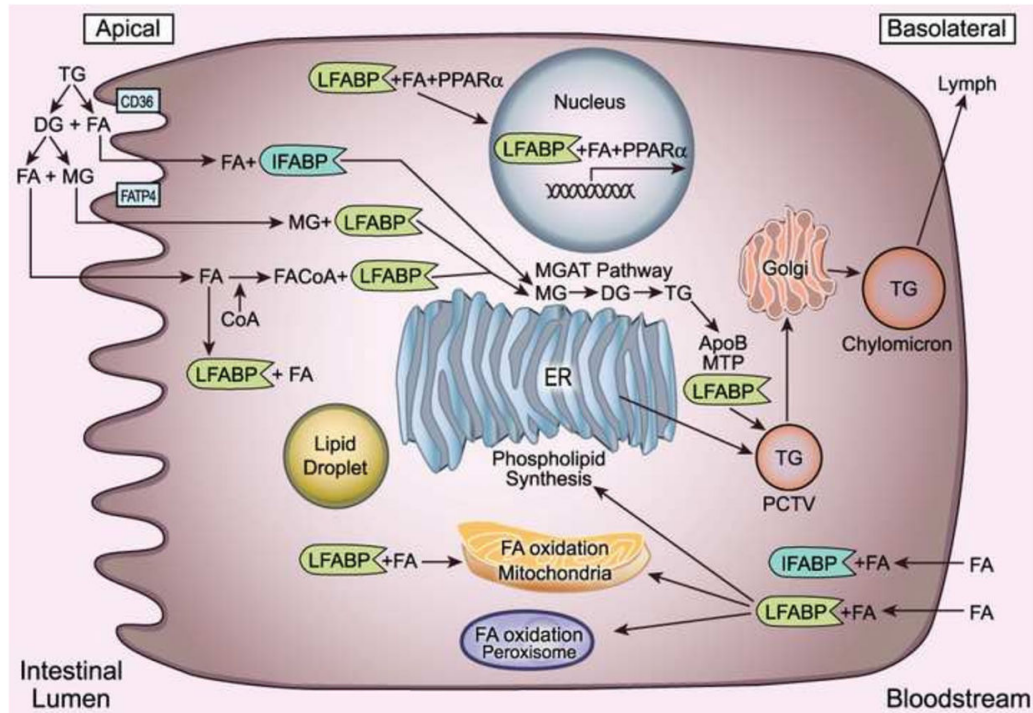

Figure 2. Function of LFABP and IFABP in intestinal enterocytes

In the intestinal lumen, dietary triacylglycerols (TG) are hydrolyzed by lipases to diacylglycerols (DG) and fatty acids (FA); the DGs are hydrolyzed to monoacyglycerols (MG) and FAs [99]. FAs and MGs are transported across the apical membrane of the enterocyte by diffusion or facilitated transport by CD36 (cluster of differentiation 36) or other putative transporters such as FATP (fatty acid transport protein) [99]. In the cytosol, IFABP specifically binds FA while LFABP binds FAs, fatty acyl-CoAs, and MGs [3,16]. In the endoplasmic reticulum (ER), FAs and MGs are resynthesized to TGs. LFABP is part of a complex along with microsomal triglyceride transport protein (MTP), CD36, and ApolipoproteinB48 (ApoB48), which is responsible for budding of prechylomicron transport vesicles (PCTV) from the ER [35,57]. PCTV then reach the Golgi apparatus where mature chylomicrons are formed. Chylomicrons leave the enterocyte via the basolateral side of the cell and enter the lymphatic system for delivery to the general circulation [99]. LFABP may also traffick FA to PPARa, promoting the expression of oxidative genes [40,41]. FAs and MGs from the circulation enter the enterocyte via the basolateral membrane where they can be bound to IFABP (FA) or LFABP (FA and MG). Unlike dietary derived lipids, bloodstream derived FAs and MGs are primarily oxidized or incorporated into PL [72,73]. 


\section{Table 1}

A comparison of the phenotypes of $\mathrm{IFABP}^{-/-}$and $\mathrm{LFABP}^{-/-}$mice relative to WT fed a $45 \mathrm{kcal} \%$ fat diet (HFD) rich in LCFA.

\begin{tabular}{lcc}
\hline & IFABP $^{-/-}$ & LFABP $^{-/-}$ \\
\hline Bersus WT \\
\hline Body weight & $\downarrow$ & $\uparrow$ \\
Fat mass & $\downarrow$ & $\uparrow$ \\
Food intake & $\downarrow$ & $\uparrow$ \\
Respiratory exchange ratio & $\uparrow$ & $\downarrow$ \\
Energy expenditure & $\leftrightarrow$ & $\leftrightarrow$ \\
Activity & $\leftrightarrow$ & $\uparrow$ \\
Intestinal TG secretion & $\uparrow$ & $\leftrightarrow$ \\
Bloodstream FA, TG/PL & $\downarrow$ & $\downarrow$ \\
Dietary FA, TG/PL & $\leftrightarrow$ & $\leftrightarrow$ \\
Intestinal FA oxidation & $\leftrightarrow$ & $\downarrow$ \\
\hline
\end{tabular}

